\section{Effects of delayed and trace components of a compound CS on conditioned} suppression and heart rate*

\author{
ALAN J. BORGEALT, JOHN W. DONAHOE, and ALEXANDER WEINSTEIN† \\ University of Massachusetts, Amherst, Mass. 01002
}

Following 150 classical conditioning trials with a compound CS paired with shock, barpressing and heart-rate responses to the first, $\left(S_{1}\right)-$, and second, $\left(\mathrm{S}_{2}\right)-$, occurring components and to the compound $\left(\mathrm{S}_{1_{2}}\right)$ were assessed using a conditioned suppression procedure. The decrease in barpressing and heart rate to $S_{1}$ was greater than to $S_{2}$ in the group of rats $(N=12)$ in which $S_{1}$ and $S_{2}$ overlapped during conditioning $\left(S_{1}\right.$-delay group). In the $S_{1}$-trace group $(N=12)$, in which $S_{1}$ and $S_{2}$ were presented successively, $S_{2}$ was a more effective suppressor than $S_{1}$. The presence of cardiac acceleration during conditioning but deceleration during testing was attributed to the effects of barpressing activity on heart rate.

The thrust of much recent work with compound conditioned stimuli is that the behavioral control exerted by the components and by the compound cannot be predicted solely from knowledge concerning the strength of conditioning as a function of CS-US interval. That is, the greatest control is not always exerted by that component which precedes the US by an interval which leads to optimal control with a single CS. A phenomenon which exemplifies the foregoing is informativeness. In a study illustrating the informative effect, two partially overlapping CSs preceded food and the first-occurring stimulus $\left(S_{1}\right)$ was found to serve as a more effective conditioned reinforcer than the second-occurring stimulus $\left(\mathrm{S}_{2}\right)$, even though temporal factors favored $\mathrm{S}_{2}$ (Egger \& Miller, 1962). In contrast to the foregoing result, when two stimuli preceded shock in a conditioned suppression study conducted in this laboratory, $S_{1}$ and $S_{2}$ suppressed performance about equally, with $S_{2}$ tending to be somewhat more effective (Ayres, 1966). A possible source of the disagreement regarding the relative efficacy of the components of a compound CS in conditioned reinforcement and conditioned suppression is as follows: in the study of conditioned suppression, only a small number (10) of CS-US pairings were given, whereas in the study of conditioned reinforcement a much larger number (135) of pairings were given. That the number of pairings

*The research was supported by U.S. Public Health Service Grants MH 10706 and MH 17395 to the second author. Requests for reprints should be sent to John W. Donahoe, Psychology Department, Middlesex House, University of Massachusetts, Amherst, Mass. 01002

+Now at Frostburg State College, Frostburg, Md. 21532. may be a critical variable in determining the relative effectiveness of the components of a compound CS is indicated by a study of conditioned reinforcement using nonoverlapping successive components in which $\mathrm{S}_{2}$ was the more effective component with a small number of pairings but $S_{1}$ was more effective with an increased number of pairings (Thomas, Berman, Serednesky, \& Lyons, 1968).

The objective of the present experiment was to redetermine the relative control of conditioned suppression by $S_{1}$ and $S_{2}$ after a larger number of pairings with shock than previously employed by Ayres (1966). Concomitantly with conditioning trials, heart-rate measures were taken to determine if some indication of a change in the conditioned cardiac response foreshadowed a change in the relative suppression associated with $S_{1}$ and $S_{2}$ in the later test for conditioned suppression. Both a procedure in which $S_{1}$ and $S_{2}$ were partially overlapping components $\left(S_{1}\right.$-delay group) and a procedure in which $S$, and $S_{2}$ were nonoverlapping successive employed.

Twenty-four male albino rats (Sprague-Dawley strain), 100 days old at the outset of the experiment, served as Ss. All Ss were maintained on a $22-h$ deprivation schedule at $80 \%$ of their free-feeding weights.

Four operant chambers were used, two of which had been employed in the prior study of conditioned suppression (Ayres, 1966). Each chamber contained a retractable response bar, a grid floor through which scrambled shock could be delivered, and a ceiling-mounted enclosure which held the speaker and lamps used to produce the components of the compound CS. As components ( $S_{1}$-trace group) were measured in the vicinity of the response bar, the speaker provided a $1,000-\mathrm{Hz} 88-\mathrm{dB}$ tone and the lamps a 13.5-fc white light. The chambers were housed in individual sound-attenuating hulls, with blowers furnishing ventilation and an $85-\mathrm{dB}$ white noise serving as a masking stimulus. The experiment was controlled by switching and timing circuitry located in an adjacent room, and responses were recorded by a printing counter. The electrical changes accompanying heart beats were monitored via surface electrodes held in place by a Velcro strap which encircled the shaved thoracic area of the rat. Wound clips coated with electrode paste served as electrodes. The heart-rate and barpressing responses originating from the four chambers and the stimuli $\left(S_{1}\right.$, $S_{2}$, and the compound $S_{12}$ ) were simultaneously recorded on a Grass polygraph at a paper speed of $25 \mathrm{~mm} / \mathrm{sec}$.

The experiment consisted of five stages which paralleled the investigation by Ayres (1966): (1) A baseline barpressing level was established through two sessions of continuous reinforcement and six $52-\mathrm{min}$ sessions of variable-interval 60-sec (VI-60) reinforcement with $45-\mathrm{mg}$ food pellets. (2) The unconditioned effects of the stimuli on barpressing prior to being paired with shock was assessed during a seventh session of VI-60 reinforcement. During this session, the light, tone, and the light-tone compound were each presented for two $2 \cdot \mathrm{min}$ periods. The mean interpresentation interval was $8 \mathrm{~min}$, and the order of presentation was balanced across the two groups of 12 Ss. Because of a procedural error, heart-rate records were inadvertently not taken during the session, although the recording electrodes were in place. (3) Classical conditioning trials were next administered with the bar retracted from the chamber. All Ss received $10 \mathrm{CS}$-US pairings during each of 15 consecutive sessions for a total of 150 pairings. For the $S_{1}$-delay group, the CS consisted of $S$, for $4 \mathrm{sec}$ followed by $S_{1}$ and $S_{2}$ together for 11 sec. For the $S_{1}$-trace group, the CS consisted of $S_{1}$ for $4 \mathrm{sec}$ followed by $\mathrm{S}_{2}$ alone for 11 sec. For both groups, a $2-\mathrm{mA}$ shock occurred during the final $.5 \mathrm{sec}$ of the CS. The mean intertrial interval was $4.8 \mathrm{~min}$ with a range of from 2 to $8 \mathrm{~min}$. The duration and intensity of $S_{1}, S_{2}$, and shock were identical to those used by Ayres (1966). For half the $S s$ in each treatment group, the tone served as $S_{\text {, }}$ and the light as $S_{2}$; for the other half, the relationship was reversed. (4) Recovery of the baseline level of barpressing was accomplished by 
giving all Ss five sessions of VI-60 reinforcement with no lights, tones, or shocks being presented. (5) As a test of conditioned suppression, all Ss were given five daily sessions of VI-60 reinforcement during which $S_{1}, S_{2}$, and $S_{12}$ were each presented twice in the same manner as had occurred during the initial assessment of the unconditioned effects of the stimuli. No shocks were administered.

\section{RESULTS}

The heart rate during conditioning was analyzed on odd-numbered sessions $(1,3,5, \ldots, 15)$. The baseline heart rate was $363 \mathrm{bpm}$, and the UR to shock was an acceleration to $452 \mathrm{bpm}$. As measured against the baseline rate obtained from the five interbeat intervals prior to the onset of $S_{1}$, the major change in heart rate was an acceleration which occurred during the terminal portion of $\mathrm{S}_{2}$ prior to shock onset. By the seventh CS-US pairing, the accelerative response was statistically reliable $(p<.025)$ and increased in magnitude to a maximum of $8 \%$ above baseline during the third conditioning session. As the conditioning sessions continued, however, the magnitude of acceleration declined and essentially disappeared by the 15 th conditioning session when a nonsignificant acceleration of only $0.6 \%$ was observed. The aforesaid change in the pattern of response from acceleration to an absence of effect as a function of conditioning sessions was highly reliable $\quad\left(F=14.69, \quad \mathrm{df}=7 / 440,{ }^{1}\right.$ $\mathrm{p}<.001)$. No differences in the heart-rate response were found between the $S_{1}$-delay and $S_{1}$-trace groups.

In the test for conditioned suppression, the degree of suppression was measured by the ratio of the number of responses occurring within the stimulus to the sum of the number of responses occurring within the comparable time period preceding the stimulus and during the stimulus (Annau \& Kamin, 1961). Thus, a suppression ratio of 0.0 represents complete suppression, while a ratio of .5 represents no suppression. As assessed during the baseline session prior to the pairing of the stimuli with shock, the unconditioned effects of $S_{1}, S_{2}$, and $S_{12}$ on barpressing were negligible- $.50, .46$, and .45 , respectively-and were not different for the two CS groups. The suppression produced by the components and the compound on test days are shown in Fig. 1. The relative effectiveness of the $S_{1}$ and $S_{2}$ components was a function of whether $S_{1}$ was a delayed (upper portion of Fig. 1) or a trace (lower portion) CS $(\mathrm{F}=7.86, \mathrm{df}=1 / 40, \mathrm{p}<.01)$. In the $\mathrm{S}_{1}$-delay group, $\mathrm{S}_{1}$ produced more

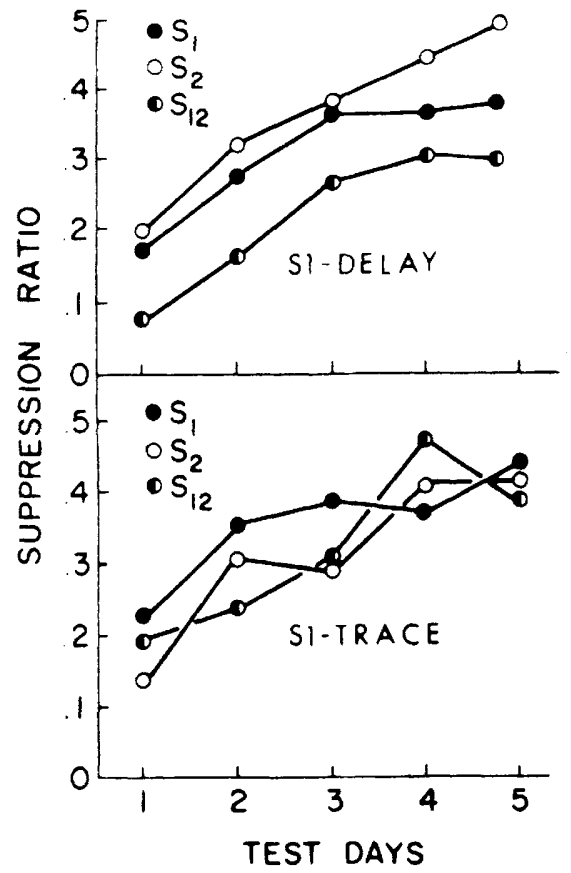

Fig. 1. Conditioned suppression produced by the $S_{1}$ and $S_{2}$ components and by the $S_{12}$ compound in the $S_{1}$ delay and $S_{1}$-trace groups.

suppression than did $S_{2} \quad(p<.05$, one-tailed) in contrast to the results of the earlier experiment in which a smaller number of conditioning trials were administered (Ayres, 1966). In the $S_{1}$-trace group, $S_{2}$ produced greater suppression than did $S_{1}$ ( $p<.05$, one-tailed). With respect to the suppression produced by the compound, $\mathrm{S}_{12}$ produced relatively more suppression than did the components in the $\mathrm{S}_{1}$-delay group as compared to the $S_{1}$-trace group $(F=11.01, \quad$ df $=1 / 40, \quad p<.005)$. Within the $S_{1}$-delay group, the compound was more suppressing than the components $(p<.01)$, whereas $\mathrm{S}_{12}$ did not differ from the components in the $S_{1}$-trace group $(p>.20)$. The degree of suppression was unaffected by the modality of the stimulus (light vs tone), but there was a tendency for the tone to produce greater suppression than the light when used as a trace CS in the $S_{1}$-trace group $(p<.05)$. The heart rate response during the test of conditioned suppression was a deceleration for all stimuli and both treatment groups. From a baseline heart rate of $383 \mathrm{bpm}$, which was significantly $(p<.01)$ above the baseline observed during the conditioning sessions (when Ss were not barpressing), the heart rate decreased approximately $6 \%$, with the magnitude of the decrease varying with the stimulus. Considering first the response to the components, the decrease was greater to $S_{1}$ than to $S_{2}$ within the $S_{1}$-delay group $(p<.001)$, whereas the decrease was nonsignificantly greater to $\mathrm{S}_{2}$ within the $S_{1}$-trace group $(p>.20)$. This resulted in a reliable Components by Groups interaction $(F=9.51$, $\mathrm{df}=1 / 40, \quad \mathrm{p}<.005)$. The $\mathrm{S}_{12}$ compound produced more deceleration than the components independent of the treatment group $(p<.01)$. The amount of deceleration declined across the five test sessions for all stimuli $(\mathrm{F}=19.47, \mathrm{df}=4 / 71$, $\mathrm{p}<.001)$.

When $S_{1}$ and $S_{2}$ overlap and a sufficiently large number of CS-US pairings are given as in the $S_{1}$-delay group, $S_{1}$ becomes a more effective suppressor of performance than $S_{2}$. The above finding brings the conditioned suppression literature into agreement with the effects of comparable training conditions on conditioned reinforcement (Egger \& Miller, 1962, 1963). If $S_{1}$ and $S_{2}$ are presented successively without overlapping, as in the $S_{1}$-trace group, $\mathrm{S}_{2}$ remains the more effective suppressor after 150 CS-US pairings. Unless further training is shown to alter the relative effectiveness of the components within the $S_{1}$-trace group, the most parsimonious interpretation of the present findings regarding the suppression produced by $S_{1}, S_{2}$, and $S_{12}$ is as follows: The suppression during test sessions is greatest for those stimuli which are present during conditioning and occur in closest proximity to shock delivery. In the $S_{1}$-delay group, $S_{12}$ was present during conditioning and immediately prior to shock, $S_{1}$ was present during conditioning but not presented alone immediately prior to shock, and $\mathrm{S}_{2}$ was never presented alone prior to shock. Thus, the similarity of training to testing conditions for the various stimuli was ordered in the same manner as their relative suppressiveness. In the $S_{1}$-trace group, $\mathrm{S}_{2}$ was presented alone immediately prior to shock, whereas $S_{1}$ was disadvantaged by not appearing immediately prior to shock and $\mathrm{S}_{12}$ was disadvantaged by never being presented during training. While generalization decrement between training and testing conditions has sometimes been offered as an interpretation of the information effect generally (Kamin \& Mertl, 1960), the occurrence of the effect with successive compounds and the development of configuring (Thomas et al, 1968) argue for the efficacy of additional variables. A priori, a more pronounced generalization decrement might be anticipated in the 
conditioned suppression and avoidance (Bellingham \& Ferraro, 1968) paradigms, since, in contrast to the conditioned reinforcement and conditioned punishment (Seligman, 1966) paradigms, the criterion response occurs contemporaneously with the stimuli whose control is being assessed.

Two comments might be made with respect to the changes in the cardiac response which were observed in the present experiment. First, additional research should be conducted to determine whether changes in the pattern of the cardiac response-such as the disappearance of acceleration found during the conditioning phase of this study-presage changes in the relative effectiveness of the components of compound CSs. Secondly, the fact that the baseline level of the heart rate increased during testing when the Ss were barpressing together, with the increase in heart rate to the CS occurring during conditioning but the decrease occurring during testing, suggests that the state of the barpressing response strongly influenced the cardiac response. The interaction between the barpressing and cardiac response systems may underlie the previously reported finding that the UR was acceleration but that the response to the CS was deceleration when conditioned suppression was acquired concurrently with barpressing (deToledo \& Black, 1966). What is suggested here is that the accelerative $C R$ may have been masked in the earlier study by the deceleration produced by the cessation of barpressing.

\section{REFERENCES}

ANNAU, Z., \& KAMIN, L. J. The conditioned emotional response as a function of intensity of the US. Journal of Comparative \& Physiological Psychology, 1961, 54, 428-432.

AYRES, J. J. B. Conditioned suppression and the information hypothesis. Journal of Comparative \& Physiological Psychology, 1966, 62, 21-25.

BELLINGHAM, W. P., \& FERRARO, D. P. $A$ test of the information hypothesis in an avoidance paradigm. Paper read at Midwestern Psychological Association,
Chicago, May 1968

deTOLEDO, L., \& BLACK, A. H. Heart rate: Changes during conditioned suppression in rats. Science, 1966,152, 1404-1406.

EGGER, M. D., \& MILLER, N. E Secondary reinforcement in rats as a function of information value and reliability of the stimulus. Journal of Experimental Psychology, 1962, 64, 97-104.

EGGER, M. D., \& MILLER, N. E. When is a reward reinforcing?: An experimental study of the information hypothesis. Journal of Comparative \& Physiological Psychology, 1963, 56, 132-137.

KAMIN, L., \& MERTL, R. The Egger and Miller "redunciancy" data: An alternative interpretation. Paper read at the Psychonomic Society, St. Louis, October 1960.

SELIGMAN, M. E. P. CS redundancy and secondary punishment. Journal of Experimental Psychology, 1966, 72, 546-550.

THOMAS, D. R., BERMAN, D. L., SEREDNESKY, G. E., \& LYONS, J. Information value and stimulus configuring as factors in conditioned reinforcement. Journal of Experimental Psychology, 1968, 76, 181-189. NOTE

1. In those instances in which the heart rate record was unscorable due to movement artifact or noise, the missing data were estimated and the df for error appropriately reduced.
Physiological Factors

BAILE, C. A., ZINN, W., \& MAYER, J. Feeding behavior of monkeys: Glucose utilization rate and site of glucose entry. Physiology \& Behavior, 1971, 6, 537-541.

BELL, D. D., \& ZUCKER, I. Sex differences in body weight and eating: Organization and activation by gonadal hormones in the rat. Physiology \& Behavior, 1971, 7, 27-34.

EHMAN, G. K., ALBERT, D. J., \& JAMIESON, J. L. Injections into the duodenum and the induction of satiety in the rat. Canadian Journal of Psychology, 1971, 25, 147-166.

GLICK, Z., THOMAS, D. W., \& MAYER, J. Absence of effect of injections of the intestinal hormones secretin and cholecystokinin-pancreozymin upon feeding behavior. Physiology \& Behavior, 1971, 6, 5-8.

HAMILTON, L. W. Starvation induc $\curvearrowright$ d by sucrose ingestion in the rat: Partial protection by septal lesions. Journal of Comparative \& Physiological Psychology, 1971, 77, 59-69.

HATTON, G. I. Time course of blood changes during acute water deprivation in rats. Physiology \& Behavior, 1971, 7, 35-38.

HOUPT, T. R., \& HANCE, H. E. Stimulation of food intake in the rabbit and rat by inhibition of glucose metabolism with 2-deoxy-d-glucose. Journal of Comparative \& Physiological Psychology, 1971, 76, 395-400.

KOZUB, F. J. Drinking produced by blood volume manipulation in weanling and adult rats. Psychonomic Science, 1971, 25, 19-20.

MESSING, R. B., \& CAMPBELL, B. A. Dissociation of arousal and regulatory behaviors induced by hypertonic and hypovolemic thirst. Journal of Comparative \&
Physiological Psychology, 1971, 76, 305-310.

MILLER, N. E., SHAPIRO, R., K I S S I E F F, H ., \& QUARTERMAIN, D. Suppression of food intake with intragastric loading: Relation to natural feeding cycle. Science, 1971, 173, 941-943.

PANKSEPP, J. Effects of fats, proteins, and carbohydrates on food intake in rats. Psychonomic Monograph Supplements, 1971, $4(5$, Whole No. 53).

PARE, W. P. Frequency and probability of US-shock and adrenal hypertrophy in the rat. Physiology \& Behavior, 1971, 6, 493-496.

STRICKER, E. M. Effects of hypovolemia and/or caval ligation on water and $\mathrm{NaCl}$ solution drinking by rats. Physiology \& Behavior, 1971, 6, 299-303.

STRICKER, E. M. Inhibition of thirst in $r a t s$ following hypovolemia and/or caval ligation. Physiology \& Behavior, 1971, 6, 293-298. 